\title{
An Evaluation-Driven Design approach to develop Learning Environments based on Full-Body Interaction
}

\author{
Laura Malinverni* \\ Marie-Monique Schaper* \\ Narcís Pares \\ *these authors contributed equally to this work
}

\begin{abstract}
The development of learning environments based on Full-Body Interaction has become an increasingly important field of research in recent years. However, the design and evaluation strategies currently used present some significant limitations. Two major shortcomings are: the inadequate involvement of children in the design process and a lack of research into what meanings children construct within these learning environments. To tackle these shortcomings we present an Evaluation-Driven design approach, which aims at analyzing situated interpretations made by children. These interpretations are then used to guide and optimize design in an iterative process of design and assessment. This Evaluation-Driven Design method was applied in the development of the EcoSystem Project, a Full-Body Interaction Learning Environment for children aimed at supporting learning about environmental relationships. The application of this iterative approach proved to be highly effective both in facilitating continuous improvements in the proposed design and in reducing misconceptions by children using the environment. Moreover, experimental evaluation reported significant learning gains in children. This suggests both the potential of using Full-Body Interaction to support learning and the effectiveness of our Evaluation-Driven approach in optimizing design solutions through the analysis of children's interpretations.
\end{abstract}

Keywords: Full-Body Interaction; Learning Environments; Design-Based Research; Participatory Design; Evaluation; Assessment

\section{Introduction}

The goal of design is to shape ideas and project them outwards (Ackermann, 2007). When designed artifacts become present in the world, they constitute objects upon which users construct meaning by connecting them with personal interests and previous knowledge. From this perspective, the design of Interactive Learning Environments can be considered as a communication effort to express certain concepts or facilitate certain experiences. Thus, on the one hand, designers define features and qualities that may signal certain concepts or forms of usage (Norman, 1988). While on the other hand, users create their meanings by merging their own experiences with the affordances offered by the object (Jewitt, 2013). As a consequence, the relationship between the affordances of the environment and people's interpretations constitutes the foreground of the success or failure of our communication attempt (Eco, 1975) and of the learning experiences. Even if the creative nature of meaning construction is undeniable, the design of learning technologies has often focused only on the task of defining design qualities and features. Hence, design rationales have often neglected people's interpretations or relegated them to the last stage of the design process (Reeves, Herrington, \& Oliver, 2005).

Although this tendency has been widely criticized by inclusive and iterative approaches such as Design-Based Research (Barab \& Squire, 2004) or Participatory Design (Iversen \& Dindler, 2013), it still persists as a widespread practice. In particular, research approaches such as Design-Based Research and Participatory Design have been primarily integrated in desktop computer applications (Wang \& Hannafin, 2005), but are still underestimated in research related to the design of educational technologies based on novel interaction modalities.

This situation may be particularly risky. Novel interaction modalities propose different ways of interacting with technology (e.g. embodied interaction) and offer affordances and experiences that are essentially different from traditional interfaces (e.g. desktop computers). As a consequence, users may build meanings using resources that are fundamentally different from the ones offered by traditional 
interfaces (e.g. physicality, space, material artifacts, etc). This difference with respect to traditional interfaces requires designers to deepen research on how users construct meaning in these types of environments. This requirement is particularly relevant in the emerging field of Full-Body Interaction, understood as using the movements and the actions performed in physical space by the user to interact with digital technology.

From a theoretical perspective, Full-Body Interaction has the potential to support learning (Revelle, 2013). This potential is grounded on the affordances that these environments offer to involve the users at different levels (e.g. sensorimotor, cognitive and affective) and to facilitate the construction of knowledge through actions and sensorimotor experiences. Nonetheless, research on Full-Body Interaction Learning Environments (FUBILEs) has failed to offer reliable conclusions about its effectiveness (Malinverni \& Pares, 2014). Inadequate design and assessment methods could be a possible reason behind this shortcoming (Malinverni \& Pares, 2014).

Most research in FUBILEs has employed a Technology-Driven Design approach (Antle, 2013) and has focused on quantitative estimations of learning gains (Edge, Cheng, \& Whitney, 2013; JohnsonGlenberg, Koziupa, \& Birchfield, 2011; Lucht \& Steffi, 2013; Malinverni, Lopez Silva, \& Pares, 2012). These approaches systematically neglect the universes of meanings of users and the myriad variables inherent in any learning process (Reeves, Herrington, \& Oliver, 2005). This could be due to the exclusion from participation of relevant stakeholders, as well as to analyzing only expected cognitive outcomes. Furthermore, by disregarding the interplay between affordances and interpretation, the provided information becomes an inadequate basis from which to guide design or advance research in Full-Body Interaction. To tackle this issue, we suggest that research in FUBILEs should undertake a more serious analysis of how users make sense of these environments and which meanings they build from them. Such analysis will allow not only broadening research in the field, but also to feed the design process of specific FUBILEs.

Starting from this necessity, we present an Evaluation-Driven Design approach for the design and evaluation of FUBILEs. The approach is based on using children's interpretations as a central guide to inform design. Its goal is twofold. On the one hand, it aims at incorporating children's interpretations in the design of a learning environment thereby making those environments more effective in terms of specific educational goals. On the other hand, it provides tools to broaden the existing methods for evaluating FUBILEs.

To address these goals, we propose a set of techniques to elicit and analyze the meanings that children construct in a FUBILE. The outcomes of this analysis are used to guide an iterative design process. In other words, the design is driven by findings from empirical research and refinements are built upon the analysis of user-generated meanings.

In the following sections we will introduce the context of the current research and the proposed Evaluation-Driven Design approach. We will, then, describe the use of this approach in the design and development of a novel FUBILE, the EcoSystem Project. Subsequently, we will discuss the effectiveness of the proposed approach in facilitating continuous improvements during the design of the EcoSystem Project. Finally, we will conclude by analyzing the strengths and limitations of the proposed approach.

\section{Full-Body Interaction Learning Environments: Current Limitations}

Research in educational technologies has a long-standing trajectory related to the debate known as "the media effect on learning" (Kozma, 1994). Today it is generally acknowledged that a specific medium can affect learning because of its affordances (Nathan \& Robinson, 2001). Several studies have been dedicated to evaluating how different interaction modalities can be particularly suitable to support learning (Kim \& Maher, 2008; Lucignano, Cuendet, S. Schwendimann, Shirvani Boroujeni, M. Dehler, \& Dillenbourg, 2014). Building on this idea, Full-Body Interaction represents an emergent field of research and several FUBILEs have been developed addressing different aspects of learning such as musical concepts (Antle, Droumeva, \& Corness, 2008), second language (Edge et al., 2013) or physics related concepts (Malinverni et al., 2012). Research in this field is grounded on theoretical frameworks derived from cognitive science (Barsalou, 2008; Goldin-Meadow, 2011; Wilson, 2002), developmental psychology (Clearfield, 2004; Iverson, 2010) and pedagogy (Ackermann, 2004).

According to the theory of Embodied Cognition, our body and its interaction with the environment helps us understand the world and support learning processes (Barsalou, 2008; Kontra, Goldin-Meadow, \& Beilock, 2012). Research in this area has shown how physical states and experiential opportunities influence thoughts and knowledge construction (Wilson, 2002). As a consequence, it suggested that embodied experiences may facilitate us to construct multimodal representations that are then re-enacted when knowledge is needed (Barsalou, 2008). This perspective is consistent with research in developmental psychology, which has shown the fundamental role of sensorimotor experiences in the development of fundamental cognitive skills. For instance, studies have shown important relationships 
between the acquisition of specific motor skills and the development of language (Iverson, 2010) or spatial cognition (Clearfield, 2004). At the same time, research in learning contexts has shown that having children perform specific gestures during instruction can contribute to a better understanding of mathematical concepts (Goldin-Meadow, 2011) and that children's manipulation of physical prompts supports a better recall of related narratives (Glenberg, Brown, \& Levin, 2007). The evidence produced by these studies and the importance gained by constructive pedagogies, lead the educational community to promote the need for approaches capable of actively and experientially involving the learners. Starting from the idea that learning is more fruitful when anchored on meaningful and concrete activities (Jonassen \& Rohrer-Murphy, 1999) a wide variety of active and experiential pedagogical approaches have been proposed (Kolb, Boyatzis, \& Charalampos, 2001; Papert, 1980).

Building on this perspective, research on FUBILEs has provided some promising results. Specifically, it showed how Full-Body Interaction may facilitate a higher level of social interaction (Malinverni \& Pares, 2015), better retention of knowledge (Enyedy, Danish, Delacruz \& Kumar, 2012; Johnson-Glenberg et al., 2010) and more satisfactory user experience (Adachi et al., 2013; Antle, Corness, \& Bevans, 2013) with respect to traditional interfaces. Nonetheless, a review of the research in this field (Malinverni \& Pares, 2014) showed how findings in this area offer a scattered and sometimes inconsistent panorama, from which it is not possible to derive robust conclusions. Furthermore, due to the novelty of the field, several shortcomings in design and evaluation methods have also been identified (Malinverni \& Pares, 2014).

At a design level, most projects derive from a Designer-Driven approach in which children and teachers are rarely involved in the design process (Antle et al., 2013, 2008; Carreras \& Parés, 2004; Charoenying, Gaysinsky, \& Ryokai, 2012; Edge et al., 2013). Just few FUBILEs involve teachers in the design as, for instance, the projects Learning Physics (Enyedy et al., 2012) and PUSH (Johnson-Glenberg et al., 2010). Instead, to our knowledge only the FUBILE IGameFloor (Grønbæk et al., 2007) involves both teachers and children in the design process. The general tendency to leave out the users from the design process is unaligned with the emergent recommendations from the Human Computer Interaction community to involve end-users at a deeper level in the design process (Muller \& Druin, 2003).

Moreover, this trend leads designers to mainly focus on defining specific affordances, without taking into account how users make sense of and construct meaning during the experience. As a consequence, many projects of FUBILEs use a top-down workflow, which means that design always precedes assessment and the way in which children interpret and use the system is rarely used to further inform and refine design. Furthermore, even in cases where end-users are involved in the design process, their involvement is mainly focused on usability testing without considering higher-level aspects such as meaning construction and situated action.

On the other hand, at an assessment level, projects aimed at evaluating the educational effectiveness of FUBILEs are mainly based on a stimulus-response model of learning. Although Kozma (1994) pointed out, already quite some years ago, the inadequacy of the stimulus-response model for evaluating the media effects on learning, most FUBILE projects still focus their evaluation only on what can be assessed by quizzes such as multiple-choice questionnaires (Anastopoulou, Sharples, \& Baber, 2011; Edge et al., 2013; Johnson-Glenberg, Koziupa, \& Birchfield, 2011; Kynigos, Smyrnaiou, \& Roussou, 2010; Lucht \& Steffi, 2013; Malinverni et al., 2012). Multiple-choice questionnaires limit research to evaluating whether children give the "correct" answer. Hence, they automatically exclude a deeper understanding of the meanings that are being created by children (Reeves \& Okey, 1996) and fail in properly discriminating the reasoning process behind the answers (Berg \& Smith, 1994). Furthermore, multiple-choices questionnaires focus on factual knowledge which radically contradicts the "constructivist framework" on which many projects claim to be based. According to constructivism, learning is an active process in which learners construct new ideas and concepts based on their previous knowledge (Bruner, 1962). It is, therefore, in opposition to those tools that assess only the level of factual knowledge acquired by the subjects.

These issues are particularly relevant in contexts such as FUBILEs, where novel ways of learning are proposed (e.g. embodied learning) and which consequently need to be properly evaluated and understood. At the same time, the identified drawbacks outline an epistemological incongruence between the claims related to embodied learning and its application in the design and evaluation process.

Embodied Cognition suggests that cognition and knowledge cannot only be restricted to the mind but that they arise in the relation between the mind, the body and the world (Wilson, 2002). However, the focus on cognitive aspects assessed by quizzes and the lack of analysis of situated construction of meaning, intrinsically contradict this claim. This incongruence outlines the need for design and evaluation approaches capable of coherently fitting with the embodied learning framework and taking full advantage of the potential of Full-Body Interaction. We, thus, suggest that combining the analysis of user interpretations with a greater involvement of end-users and experts in the design process may benefit 
research in FUBILEs both at the pragmatic level of designing a specific environment, as well as at the theoretical level of expanding available knowledge in the field.

\section{An Evaluation-Driven Design Approach}

The identified limitations in the design and evaluation of FUBILEs point out the need for a critical reflection upon the currently employed methods to delineate possible approaches capable of coherently fitting with the theoretical framework upon which FUBILEs claim to be based. Taking embodied cognition seriously requires moving beyond reductionist and positivist epistemologies (Harrison, Sengers, \& Tatar, 2011) which tend to limit the notion of the learning process as one which is based on knowledge transfer only. As a consequence, new methods must embrace relational and situated epistemologies (Overton, 2004) capable of dealing with the complexity inherent to any learning experience.

Relational epistemology proposes a holistic approach which considers that the identity of objects, events and people derives from the relational contexts in which they are embedded (Overton, 2004). Therefore, it conceptualizes knowledge and meaning as ongoing processes, rather than as objects that exist "out there" or "in the mind of somebody" and that can be directly accessed by or delivered to others (Forsythe, 1993). From a design and evaluation perspective, this approach implies having to reconsider what we are designing and what we are evaluating.

To address this issue we propose an Evaluation-Driven approach to design and evaluate FUBILEs. The approach is based on considering the notion of user-generated meanings as the minimal unit of analysis. This notion refers to the meanings constructed by the users in the iterative connection between the meaning potential of an artifact, the user's previous knowledge and the features of sociocultural context (Jewitt, 2013). Thus, it proposes using user-generated meanings as a central guide to inform design.

To apply this approach to design requires extending the current focus beyond the definition of object's affordances and encompassing a broader perspective capable of including the analysis of users' previous knowledge, interests and interpretations. At the same time, from an evaluation perspective, it requires the analysis of the meanings that are currently constructed and not only the ones that are expected by the designers (Kress, 2010) as is the case of multiple choice questionnaires.

At a methodological level we define our approach by integrating and articulating techniques coming from Participatory Design (Druin, 2002; Muller \& Druin, 2003), Design-Based Research (Barab \& Squire, 2004; Wang \& Hannafin, 2005), Formative Assessment (Nicol \& Macfarlane- Dick, 2006) and Grounded Theory (Corbin \& Strauss, 1990). Participatory Design and Formative Assessment techniques allow us to grasp users' previous knowledge, interests, understanding and socio-cultural values and to incorporate them in the design process (Muller \& Druin, 2003). In our approach, these techniques were applied as tools to elicit users' contributions. In particular, we applied them to elicit children's representations, previous knowledge, misconceptions and core meanings (i.e. what children consider relevant to select, remember and recall).

However, our goal was not only to provide a descriptive account of the meanings that are constructed in a FUBILE, but also to use them as informative instruments to guide the design. For this purpose, we draw from Design-Based research to structure the workflow as an iterative design and assessment cycle. By considering design and assessment as inseparable instances, mutually reinforcing and informing each other, this structure allows us to constantly evaluate how the designed environment acquires meaning through user interpretations. Finally, Grounded Theory, understood as a methodological approach to inductively derive meaning from data, was used to analyze children's interpretations and their situated interaction with the FUBILE. From the previously defined techniques we elaborated the design and assessment workflow described in Figure 1.

To sum up, the Evaluation-Driven approach proposes an iterative design process where the analysis of user interpretations, core meanings, misconceptions and situated interaction is employed to inform and refine design. For this purpose, it suggests a set of techniques aimed at facilitating this analysis. Our hypothesis is that the analysis of user-generated meanings allows the definition of guidelines for the development of a new FUBILE capable of effectively supporting learning. In the following sections we will describe how we applied the Evaluation-Driven approach in the development of a FUBILE aimed at supporting learning about environmental relations and pollution. 


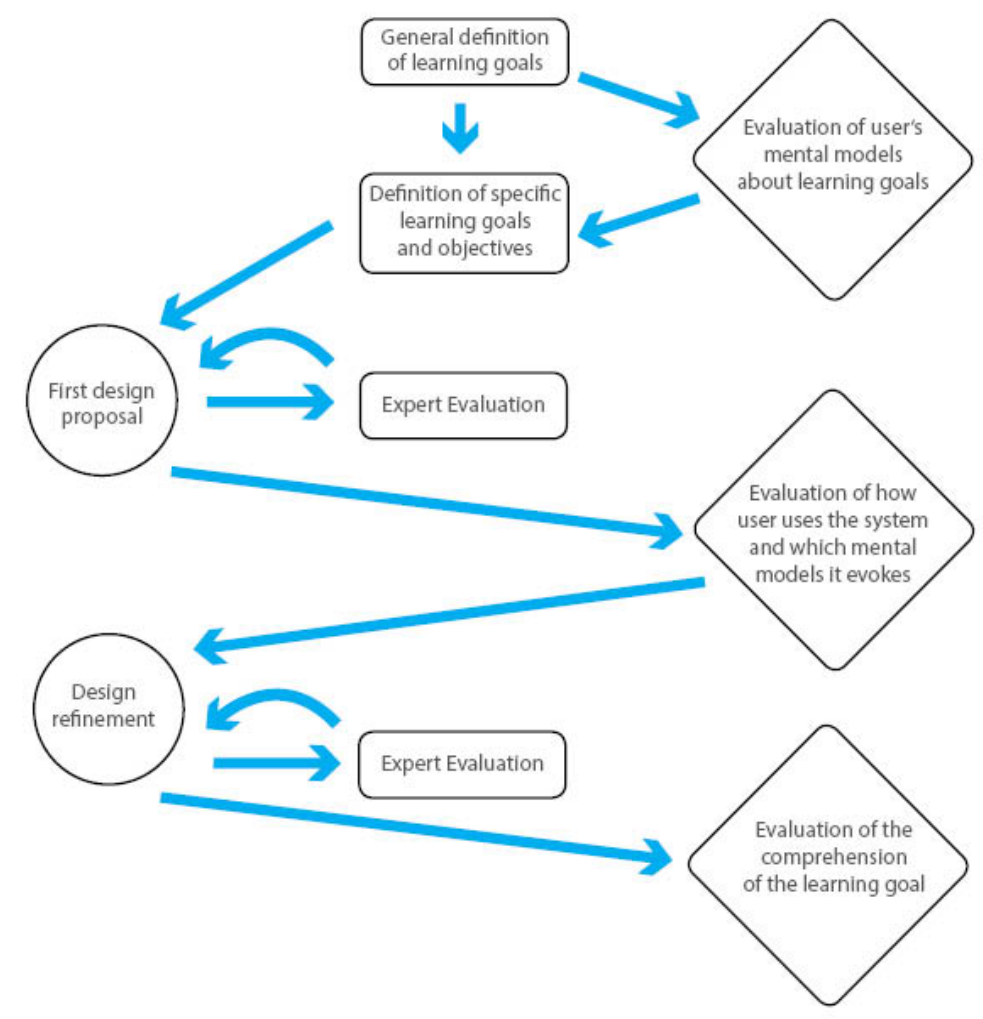

Figure 1. Workflow of the Evaluation-Driven Design process

\section{The Study for the EcoSystem Project}

For this study, we applied the proposed Evaluation-Driven approach to the development of the project EcoSystem, a FUBILE aimed at supporting learning of concepts related to environmental education. For this project, we formalized the Evaluation-Driven approach in a three-stage procedure aimed at creating continuous iterations and an on-going feedback loop between design and assessment. The goal of the procedure was to define an iterative path to guide the design process from an initial ideation phase toward the evaluation of a prototype. For this purpose, children's participation during the process was modulated according to the different roles of children's involvement proposed by Nesset \& Large (2004); i.e. co-designers, informants and testers. For all three stages, we worked with children between 10 and 12 years old. Children came from different schools and each class group participated in only one of the three consecutive stages. In all three, they came from middle class urban public schools located in the city of Barcelona, Spain.

Formally, the procedure was organized as follows:

1. Stage 1: Children as co-designers

This first stage of the study had the goal of defining the educational needs through the use of Participatory Design methods. For this purpose, we analyzed children's representations, previous knowledge and misconceptions on concepts related to environmental education. Then, we employed them to define design requirements and to develop a first prototype of the game.

2. Stage 2: Children as informants

The second stage of the study had the goal of analyzing children's interaction and interpretation of the first prototype. This analysis was oriented toward using their feedback as instruments to refine our design proposal.

3. Stage 3: Children as testers

The third stage of the study aimed at evaluating the effectiveness of the designed FUBILE in supporting learning and comparing its use with traditional instructional methods. 


\section{Stage 1: Children as Co-Designers}

The goal of the first stage was to define specific learning goals according to experts' requirements and children's understandings of concepts related to environmental education. For this purpose, we initially collaborated with experts in environmental education from the "Centre for Environmental Education La Fabrica del Sol" (Barcelona). In this first stage, we carried out two meetings with experts. During the meetings, experts did not propose any clearly defined goals, but instead focused on defining the main current general objectives of environmental education (e.g. renewable energies and quality of the environment, global processes, sustainability in use of the resources, etc.). This broad spectrum of potential learning goals gave space for better defining the final goals according to children's interests and previous knowledge.

Subsequently, in order to frame more precisely the addressed learning goals, we carried out a Participatory Design (PD) workshop with children. The aim of the PD workshop was to ground learning goals on children's interests and previous knowledge and to understand the representations that children hold around environmental education. We embraced this goal by examining children's misconceptions and their core meanings on the topic. Through this approach we aimed at identifying knowledge gaps that needed to be addressed as learning goals. Furthermore, our analysis was oriented toward defining concepts that can bridge the gap between what children already know and novel knowledge, in order to use children's previous knowledge as an entry path for the comprehension of novel concepts (Rogoff, 1990). The findings gave us a starting point for the first design iteration. A detailed description of this study is available in (Authors)

\section{Methods}

The PD workshop was carried out on three consecutive days in our university with a total of 68 children (girls $=30$, boys $=38$ ) between 10 and 12 years old. Each of the seven sessions lasted for approximately 45 minutes. Three sessions were carried out on the first day, two sessions on the second and two on third day. The sessions were guided by two researchers and structured as follows. After a short warm-up activity, we conducted a game based on the mechanics of the board game Pictionary using terms related to the environment (e.g. solar energy). The goal of the activity was twofold. On the one hand, we wanted to evaluate which terms the children were already familiar with, their previous knowledge and misconceptions on environmental topics. On the other hand, the activity was used to explore their representations of those specific concepts.

Subsequently, children were divided into groups of four or five members and were provided with a fictitious letter from a young boy writing from the future, according to the Narrative Inquiry technique (Dindler \& Iversen, 2007). The letter was read aloud by one of the group members. Thus, the children were confronted with the critical situation of the environment in 100 years time. Starting from this letter, they were asked to write a list of positive and negative actions for the environment and to invent a game aimed at making other people aware of strategies to avoid further degradation of nature. The goal of this activity was not to produce workable games but to use game design as a strategy to delve into children's understandings about environmental issues. After a short explanation, the children produced drawings and written game descriptions. Then, each group presented their design ideas to the entire group.

\section{Results}

We analyzed the video recordings of the sessions, children's creations (i.e. drawings, lists, and written descriptions) and observers' annotations. The goal of the analysis was to identify children's previous knowledge, representations, misconceptions and core meanings related to environmental education. First, video clips were transcribed using a narrative format (i.e. a detailed description of the overall unfolding of the session, including verbal and non-verbal behaviors). Subsequently, we inductively coded children's written contributions, video transcriptions and our annotations. Coding was performed using NVivo10 according to the Grounded Theory approach (i.e. key concepts were identified and marked with a series of codes and subsequently grouped into categories). Two researchers performed the analysis and, after individual coding, reached a common agreement through several meetings.

From the analysis, we concluded that previous knowledge and core meanings of children around environmental education were mainly related to the local system of recycling and to natural elements. Out of the 26 proposed games, 14 were related to the topics of recycling or waste and the other 8 referred to plants or trees. Regarding misconceptions, we identified that in 9 out of 26 games children were wrongly applying the idea of "accumulation" to environmental aspects such as waste and watering plants. Specifically, the typical game mechanics of rewarding the player that obtains the most items, was inadequately translated into "the player that gathers most waste wins" or "the player that provides most 
water to the plants wins", which can clearly have a negative effect on the environment. Also, many children believed that the player must be rewarded for activities that are good for the environment (e.g. getting a prize for planting trees), as if the fact of helping the environment were not a reward in itself. Moreover, some children proposed to use actions that are positive for the environment (e.g. recycling or planting trees) as punishment activities for players who lost in the game.

Many topics related to abstract concepts, such as light pollution or contamination, were only associated with home practice. We also detected a lack of knowledge on global processes, such as the role of industries or specific nations. Finally, children were also not aware of their own responsibility in global processes and how their actions can have an impact on all living beings on the planet, including themselves.

\section{Outcomes}

From the analysis of the PD sessions we derived initial insights related to the definition of the learning goals and the bridging concepts. Children were already familiar with the local municipal recycling system and home practices related to saving energy or water. However, they presented relevant knowledge gaps and misconceptions about global and abstract aspects of environmental issues (e.g. pollution, the balance of the ecosystem and the interconnectedness of resources). We discussed our observations and ideas for the FUBILE with the expert in environmental education. Together with the expert, we decided to focus the learning goals of the FUBILE around the system dynamics (Zuckerman \& Resnick, 2003) of the relation between the amount of pollution and the resources available to reduce or augment it. Furthermore, to incorporate bridging concepts (Rogoff, 1990), we introduced elements such as waste reduction and plant growing in the FUBILE.

At the same time, we derived some insights to be incorporated into the game mechanics. Namely, we had observed that children presented controversial approaches related to giving extra rewards for already positive actions or using environmentally responsible behaviors as punishment for those losing in the game. This focus on extrinsic motivation was potentially harmful for promoting environmental awareness, since it gives a negative connotation to environmental responsibility. As a consequence, we decided to focus on the intrinsic motivation of caring about the environment for its own sake.

\section{First prototype: The EcoSystem Project}

The outcomes of the PD sessions were exposed to an expert in environmental education during two meetings. By merging children and expert's perspective, we designed a first prototype. The game was based on a floor projection depicting a virtual simulation of a semi-urban landscape. Children had to play in groups of four and had to collaborate with each other to reduce the amount of air-pollution in the environment. Children had to explore the existing relationships between carbon dioxide emissions and strategies for reduction and absorption of pollution. For this purpose, children played in the following three roles:

1. Wind power: producing wind energy to replace the energy produced by a steam power station and hence reduce air-pollution,

2. Plants: growing plants and vegetables to facilitate $\mathrm{CO}_{2}$ absorption and contribute to the consumption of local foods,

3. Recycling: recycling and producing compost to increase the growth of plants and reduce waste that would otherwise end up incinerated and hence increasing combustion.

Air-pollution was to be visualized as a cloud covering the game ground. Thus, as pollution increased, the amount of space available for playing decreased. In order to make the cloud decrease children needed to understand the relation between the elements present in the game (see Figure 2) and properly collaborate with other players. 


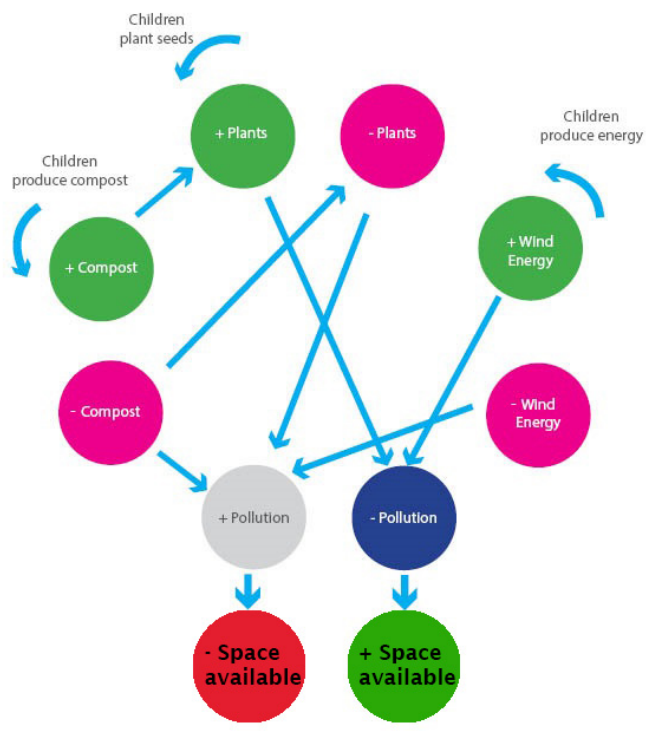

Figure 2. Behavior of the different game elements and their reciprocal relationships

\section{Stage 2: Children as Informants}

The aim of the second stage of the study was to analyze how children made sense of the environment and what meanings they constructed while playing with the EcoSystem prototype designed in the first stage. This analysis was oriented toward using their interpretations to define design refinements. The research was guided by two main questions:

- How do children interact with the environment?

- How they interpret the experience?

\section{Methods}

This second stage was carried out during one day at our university with the participation of 20 children (girls $=10$, boys $=10$ ) aged from 11 to 12 years old, who had not participated in the first stage. Before the sessions, the children were randomly separated into five groups of four. Each session lasted for approximately 30 minutes. For this study, we developed a low-tech prototype using a Wizard of $\mathrm{Oz}$ method (Markopoulos, Read, MacFarlane, \& Höysniemi, 2008). The game was projected on a 2x3 meter area on the floor and was manipulated by a researcher. To analyze how children interacted with the system the groups were randomly distributed into two conditions:

1) The Designed Actions condition: The children received explicit instructions on the physical action that they had to perform for each activity in the game with virtual and physical objects. The following actionsactivity relations were used:

- spin arms to move the propellers of the windmills to generate wind power;

- stand still for three seconds to create plants on that spot;

- grab physical rubbish cards to drop them in the correct litter container and obtain compost

2) The Intuitive Actions condition: The children did not receive any explicit instruction on the physical action that they had to perform and had to invent and improvise.

The observation of children's interaction was performed through field notes and video analysis.

On the other hand, to analyze how children understood the system we used the following techniques: an open-ended questionnaire, a conceptual map, a semi-structured group discussion and a short essay on the topic. These data were analyzed by focusing on core meanings and misconceptions. 


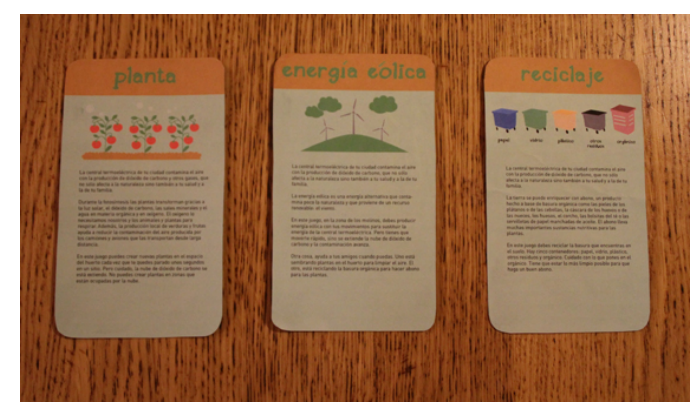

Figure 3. Role Cards: plants (left), wind power (center), recycling (right)

\section{Procedure}

One group at a time was taken to the laboratory where the FUBILE was set up. To ground their expectations, we informed them that we would use a low-tech prototype (Hanna, Risden, \& Alexander, 1997) and explained to them that they were invited to take part in the improvement of the game. Using role cards (Figure 3), we introduced the common goal and the three different interaction roles (wind power, plants, and compost). Cards were designed in collaboration with experts and provided key information about the elements in the environment and their reciprocal relations.

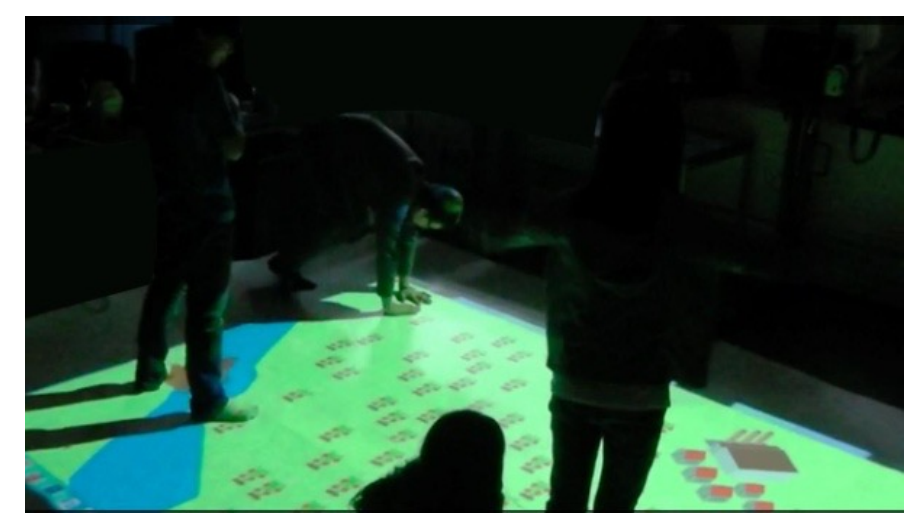

Figure 4. Floor projection of EcoSystem Project

The cards were read aloud by one child at a time and the children were invited to play for six minutes (Figure 4). When the game finished, the children individually filled out an open-ended questionnaire using pencil and paper. The questionnaire included five questions asking children to explain the role of the different elements (wind power, plants, recycling, and pollution) and their reciprocal relations. Furthermore, they were asked to propose other possibilities to reduce pollution. Subsequently, they played a second trial of the game, but this time with a larger amount of pollution. At the end of the session, participants individually filled out a conceptual map reflecting the relationships between the different elements of the game. The conceptual maps depicted the different elements present in the game. Children were asked to trace arrows to connect related elements and briefly annotate written explanations of these relationships. Finally, the individual contributions were further elaborated in a semi-structured group discussion. At the end of the session, the children were taken to a different room where they were asked to write a short letter explaining the game to a friend, describing whether they liked it or not and how it could be improved.

\section{Results}

Results were obtained by qualitative analysis of the video recordings, field annotations, semistructured discussions, questionnaires and conceptual maps.

\section{Misconceptions and core meanings}

We used content analysis based on a grounded theory approach to observe misconceptions and core meanings related to wind power, recycling, plants and system dynamics. In relation to wind power, 
nine children either did not answer or reported misconceptions. The main misconceptions were related to the idea that the movement of the windmill "blows" pollution away. This misconception could have been a consequence of the graphic design strategy used since pollution could give the impression of being "pushed away" by the windmill. On the other hand, four children related the game only to recycling and several of them mainly focused on picking up the waste from the floor. These responses may have been caused by the salience of recycling both in its representation in the FUBILE as well as in children's previous knowledge; specifically, in the prototype the waste was scattered on the floor and occupied a large area in the projected environment. At the same time, also in the previous stage, we observed that children's knowledge on environmental issues tended to basically refer to recycling. While the relation between the spatial arrangement and children's previous knowledge may have focused their attention too much on this aspect, other misconceptions also related to recycling were observed. Several children believed that picking up waste simply freed up more space on the ground and they did not understand the relation between waste and carbon dioxide. Finally, in relation to the role of plants, ten children did not answer or report misconceptions. This was apparently related to a lack of understanding of the process of photosynthesis and its relationship with the reduction of carbon dioxide through absorption by plants.

\section{Children's interaction}

To analyze children's interaction with the environment we transcribed their actions according to a narrative approach. Specifically, we contrasted the interactions of children assigned to the Intuitive Actions Condition with our proposed actions in the Designed Actions Condition. A certain consistency was present between the proposed designed actions for windmills and recycling. In the Designed Actions Condition the spinning arms movement in front of the windmill activated the wind energy. In the Intuitive Actions Condition several children also intuitively tried to spin or move their arms to activate the windmill. At the same time, the action of picking up waste and throwing it in the correct disposal was also performed by children in the Intuitive Actions Condition.

Conversely, for the role of growing plants we instructed children to perform the action of standing still for five seconds in a chosen location, impersonating the seed. The children in the Intuitive Actions Condition did not consider this action at all, but instead tended to touch or rub the floor projection as if they were sowing the seed. Furthermore, in the final essay two children, belonging to the Designed Actions Condition, reported that the assigned interaction for growing plants was "strange" and that they would like to change it.

\section{Outcomes}

Based on our results, we identified useful aspects to be considered for the development of a second prototype. Concerning design decisions, we decided to change those game elements that clearly caused misconceptions. Starting from the misconception of "air-pollution being blown away by windmills", the visualization of air-pollution was changed in order to make it more homogeneous and dynamic. Waste distribution was modified as children were focusing too much on recycling without considering other tasks. This should also overcome misconceptions related to believing that "recycling had to be done to create more space on the ground", rather than understanding that recycling is directly and indirectly connected to carbon dioxide production. Consequently, instead of being scattered over all the floor projection, waste was placed only in one specific area. Furthermore, the interaction related to plants was substituted with the action of "digging the earth" that was already performed by the children in the Intuitive Actions Condition. Finally, since the children asked for more interaction while playing the game, we decided to introduce a novel role based on the strategies that children proposed for reducing pollution. Therefore, a water power station was added to the game. Before using this new game element, we consulted the opinion of experts on environmental education. Together with the experts, we defined its representation and role in the game. With the described constraints taken into account, we developed a second prototype which was tested in a third stage of the study.

\section{Stage 3: Children as Testers}

The goal of the third stage of the study was to evaluate the proposed design approach by: (1) evaluating whether the designed FUBILE supported learning gains and (2) testing whether it could be effective to complement Traditional Instructional Methods (TIM). Our hypotheses were that:

H1: There will be a significant learning gain, measured through pre- and post-test conceptual map assessment, in children that use the FUBILE. 
$\mathrm{H} 2$ : There will be a significant learning gain in children that complement TIM with the use of the FUBILE, with respect to children that use only TIM.

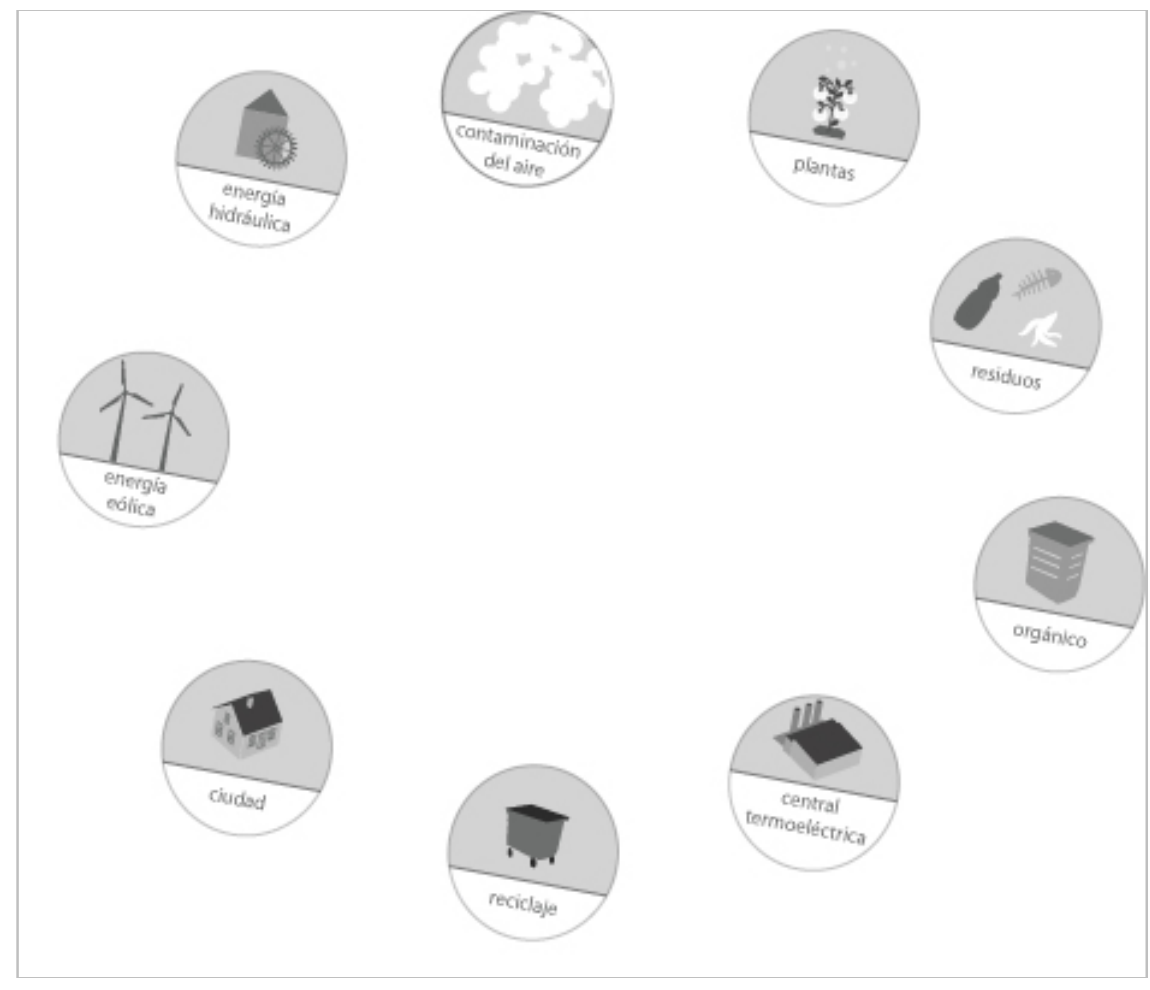

Figure 5. Representation of elements in the conceptual map designed to assess learning gain.

These hypotheses were based on the idea that the FUBILE would support learning by grounding abstract concepts in a concrete experience (Glenberg et al., 2007; Goldin-Meadow, 2011) by offering different modes of representation (Paolo, Rohde, \& Jaegher, 2007). At the same time, from the perspective of the global design process, eventual learning gains should be indicative of an alignment between designers' intentions (i.e. to communicate relationships in the ecological environment) and users' understandings.

To carry out this stage we established two conditions: and the TIM

1) The FUBILE + TIM condition, in which we evaluated the complementary use of the FUBILE

2) The TIM Only condition, in which we evaluated the use of TIM alone.

Children in this third stage did not participate in any previous phase of the research. Assessment methods were based on a conceptual map (Figure 5), a semi-structured discussion and an open-ended questionnaire.

\section{Methods}

\section{FUBILE+TIM condition}

The first phase of this stage was carried out during one day at our university. A class group of 24 new children (girls $=11$, boys $=13$; age: $M=11.52, S D=.12$ ) participated and were randomly assigned to six groups of four. At the beginning of the activity, the children were taken to a classroom where they were asked to individually fill out a conceptual map to evaluate their initial knowledge on the topic. The participants were asked to use arrows to draw connections between the different elements of the map and to give written explanations of the relationships between the connected elements. After that, one group at a time was taken to the laboratory where the FUBILE was installed. Here children were introduced to the activity and role cards (constituting the TIM) were distributed. The cards were read aloud by one child at a time. Subsequently, children played with the FUBILE for six minutes. At the end of the game children were again asked to fill out the conceptual map. A semi-structured discussion was then used to discuss the individual contributions. Finally, children individually filled out an open-ended questionnaire similar to the one used in the previous stage. Each session in total lasted for approximately 35 minutes. 


\section{TIM Only condition}

The study was carried out during one day at a primary school. A class group of 24 children participated (girls $=10$, boys $=14$; age: $\mathrm{M}=10.79, \mathrm{SD}=.41$ ) and were randomly assigned to six groups of four. At the beginning of the activity the children were asked to individually fill out the conceptual map. Then, one group at a time was taken to a separate room where role cards (TIM) were distributed.The cards were read aloud by one child at a time. After the readings, the children were taken back to the classroom and the teacher distracted them for around ten minutes with an unrelated activity (similar to the time dedicated in to playing with the FUBILE in the FUBILE+TIM phase). Finally, the assessment was repeated with a new sheet of the same conceptual map.

\section{Results}

\section{Evaluating learning gains}

To evaluate the effectiveness of the FUBILE, we analyzed the pre- and post-test of the conceptual map for both conditions (FUBILE + TIM vs. TIM Only). First, the number of correct connections was identified. Second, each explanation was evaluated by two raters according to a preestablished scale that ranged from 0 to 2 points, based on the level of correctness and completeness of the answers. Individual ratings were compared and discussed until a common agreement was found.

The results obtained were first analyzed within groups for both conditions in order to assess eventual learning gains. We performed a Shapiro-Wilk test to check for normality. Since data were normally distributed $(\mathrm{p}>0.05)$ we used parametric tests. In both cases, we used paired sample t-tests with $\alpha=0.05$. The tests reported a significant difference in the number of correct connections between pre- and post-tests. In the FUBILE+TIM condition, children reported more correct connections in the post-test $(\mathrm{M}=9.14 ; \mathrm{SD}=2.88)$ than in the pre-test $(M=6.24 ; S D=2.94), t(23)=-4.370 p<.001$. Furthermore, Cohen's effect size value $(\mathrm{d}=0.91)$ suggested a high practical significance. In the TIM Only condition, children also reported more connections in the post-test $(\mathrm{M}=6.62 ; \mathrm{SD}=2.84)$ than in the pre-test $(M$ $=5.75 ; S D=1.94), t(23)=-2.287, p=.032$. However, in this case Cohen's effect size value $(\mathrm{d}=0.48)$ suggested a small to medium practical significance. Therefore, we conclude that in both cases learning gains between pre- and post-test were obtained, but these had a greater significance in the FUBILE+TIM condition.

\section{Comparing conditions}

An independent t-test reported no significant difference in pre-test between FUBILE+TIM and TIM Only. Thus, the results of the post-tests of the two conditions were compared. By conducting an independent t-test, with $\alpha=0.05$, we found a significant difference in the number of correct connections between the two conditions. Children in the FUBILE+TIM condition $(\mathrm{M}=9.14 ; \mathrm{SD}=2.88)$ reported a significantly greater amount of connections than children assigned to the TIM Only condition $(\mathrm{M}=6.62$; $\mathrm{SD}=2.84), t(46)=-2.244, p=.03$. We conclude that using the FUBILE in combination with the TIM is more effective than using the TIM alone.

\section{Qualitative analysis}

The qualitative analysis was performed only on data from the FUBILE+TIM condition. We analyzed the open-ended questionnaires, the conceptual maps and the video recordings of the group discussions. The analysis focused on identifying novel knowledge, resolved and unresolved misconceptions and possible newly created misconceptions, both at the level of individual elements (wind power, plants, compost, water power, pollution) and in their reciprocal relations.

The comparison of conceptual maps between pre and post-test showed improvements in particular in the connections of compost with plants and renewable energies. Misconceptions were related to the connection of wind and water power to other game elements such as the steam power station. The analysis of the open-ended questionnaires detected a significant reduction in misconceptions when compared with the previous stage. The misconceptions related to the plants and recycling were eliminated. Furthermore, we observed that the children focused less on the recycling action than in the previous stage. However, the comprehension of the mechanism and role of wind power was still not clear, even when the misconception of "having pollution being blown away" had actually disappeared. Such findings suggest that the design improvements between the first and second prototypes helped children to resolve several misconceptions. However, further design improvements were still necessary since a new misconception related to the water power station emerged. For instance, six children believed that the water power station either cleaning or contaminating the water. 


\section{Outcomes}

This third stage of the study showed the effectiveness of combining traditional instructional methods with a Full-Body Interaction Experience to support learning. At the same time it supports the benefits of using the Evaluation-Driven Design approach to define design improvements. Specifically, the changes in design, based on the findings of the second stage, led to fewer misconceptions and improved understanding of some critical aspects. However, at a design level further improvements could be addressed. Especially, possible improvements could involve a better visualization of renewable energies to make the role of these elements clearer. Furthermore, this strategy could help us make the reciprocal relations between the different elements in the game much more evident and "tangible".

\section{Discussion}

In this paper we have presented an Evaluation-Driven Design approach aimed at integrating children's interpretations as central guidelines to inform the design process. Its application in the design of the Ecosystem Project allowed us guiding the development of a FUBILE capable of supporting learning. Furthermore, from a broader perspective, the present study contributes to research on design and assessment methods for novel interfaces and extends the understanding on the use of Full-Body Interaction to support learning.

\section{Design and Evaluation in FUBILEs}

The Evaluation-Driven Design approach is based on an iterative cycle of design and assessment, which focuses on analyzing the meanings that children construct and how designers employ them to guide and optimize design. Its inclusive and participatory nature confirms the importance of collaborating with end-users during the design process (Muller \& Druin, 2003). At the same time, its progressive structure endorses the effectiveness of employing cycles of refinements in design research (Barab \& Squire, 2004).

From the perspective of designing and assessing FUBILEs, the current approach offers some relevant contributions to practitioners. First of all, it moves beyond Designer-Driven or TechnologyDriven Design approaches which depend on the intuition of the designers and neglect the contribution of other stakeholders. Second, it contributes to a methodological reflection on the employed assessment methods. In particular, it presents specific contributions related to the structural organization of the research, the definition of the unit of analysis, and the employed elicitation techniques.

At a structural level, the three stages procedure (for a summary see Table 1) allowed us to tap into different aspects of meaning construction. The process of constructing meaning emerges in the interplay between the affordances of an experience and "the intentions and knowledge that people bring to that encounter" (Jewitt, 2013). Thus, our previous knowledge makes us engage with an experience in a very specific manner. Subsequently, by combining previous knowledge with the features of the experience and by reflecting on the experience, we may transform it into an object of knowledge. Our three-stages approach, therefore, allowed us to take into account different aspects that contributed to meaning construction by observing (i) children's previous knowledge (Stage One), (ii) situated interaction (Stage Two), and (iii) conceptual learning (Stage Three).

On the other hand, the definition of a broad unit of analysis based on users' interactions with the system, children's representations, previous knowledge and core meanings, allowed us to go beyond the risk of reductionism of defining a unit of analysis that is too narrow to properly observe a phenomenon; for example, focusing only on cognitive aspects through quizzes. In particular, the analysis of misconceptions and core meanings proved to be particularly effective both for defining educational needs and for guiding design improvements. Specifically, the analysis of misconceptions helped to improve the design and develop a highly effective FUBILE. An example of this process can be found in the improvements introduced between the first and the second prototypes. In the first prototype the analysis of children's core meanings and misconceptions was used to define requirements for the development of the second prototype. This approach allowed us to develop a novel prototype where the game elements that caused misconceptions were filtered. At the same time, the analysis of situated interaction through video observation proved to be a relevant instrument to provide insights for improving the interaction with the system and to suggest possible guidelines for the development of FUBILEs. Although further research is needed to corroborate these initial findings, from the analysis of the Intuitive Actions condition it seems advisable to employ intuitive gestures, based on a strict analogy with the addressed phenomenon, to design interaction with FUBILEs. Furthermore, we suggest that the analysis of intuitive user interaction could highly contribute to improve the design of FUBILEs both at the level of user experience as well as in terms of users' understandings. In this context, we are not claiming that users' 
intuitive actions necessarily need to be implemented in the final design. Instead, we suggest that, during an iterative design process, enabling conditions to observe how users intuitively interact with the environment can be highly informative to guide design refinements. For this purpose, future research may address the definition of instruments to better systematize the analysis of users' intuitive interactions in order to identify what kind of play the interface suggests and what kind of sensorimotor experience it promotes.

In relation to the employed elicitation methods, we observed that techniques proceeding from PD (e.g. game-design activity) proved to be particularly effective for gathering data about children's representations and misconceptions. Conversely, techniques such as semi-structured group discussion did not offer us valuable additional insights. These findings can be explained by considering the agentive nature of PD. In a design activity children can project and materialize their own interests and representations in the production of an artifact (Kress, 2010). As a consequence, these artifacts can provide researchers with rich data for investigating children's understandings. However, the purpose of our study was not to systematically compare elicitation techniques. Thus, further research should be carried out to explore this hypothesis. Within that, one possible research direction could address the exploration and comparison of the qualities that different PD techniques can offer to understand children's universes of meanings.

Finally, besides the methodological contributions, the current research also broadened our understanding on Full-Body Interaction and learning. The experimental evaluation of the second prototype showed a significant improvement in children's knowledge about environmental relations. Furthermore, it indicated that using the FUBILE in combination with a traditional instructional method, such as a reading activity, was more effective than the reading activity alone. These results confirmed previous findings related to the importance of using concrete experience to ground abstract concepts (Glenberg et al., 2007; Glenberg, 2010; Goldin-Meadow, 2011) and revealed the potential for using FUBILEs to complement and strengthen traditional instructional methods. At the same time, these results opened up relevant research possibilities related to evaluating the effectiveness of combining FUBILEs with other instructional methods to reinforce learning.

Table 1. Summary of the application of the Evaluation-Driven Design approach in the development of the EcoSystem Project

\begin{tabular}{|c|c|c|c|c|c|c|}
\hline Study & Goal & $\begin{array}{l}\text { Elicitation } \\
\text { technique }\end{array}$ & $\begin{array}{l}\text { Unit of } \\
\text { analysis }\end{array}$ & $\begin{array}{l}\text { Research } \\
\text { method }\end{array}$ & Outcomes & Contributions \\
\hline $\begin{array}{l}\text { First } \\
\text { stage: } \\
\text { children } \\
\text { as co- } \\
\text { designers }\end{array}$ & $\begin{array}{l}\text { Define } \\
\text { specific } \\
\text { learning goals }\end{array}$ & $\begin{array}{l}\text { Game- } \\
\text { based PD } \\
\text { Technique } \\
\mathrm{s}\end{array}$ & $\begin{array}{l}\text { Children's } \\
\text { previous } \\
\text { knowledge, } \\
\text { misconceptions } \\
\text { and core } \\
\text { meanings }\end{array}$ & $\begin{array}{l}\text { Content } \\
\text { analysis: } \\
\text { grounded } \\
\text { approach }\end{array}$ & $\begin{array}{l}\text { - Definition of area } \\
\text { of knowledge that } \\
\text { needs to be addressed } \\
\text { (systemic relation } \\
\text { between amount of } \\
\text { pollution and } \\
\text { resources to reduce } \\
\text { it) } \\
\text { - Identification of } \\
\text { bridging concepts } \\
\text { (recycling, plants) }\end{array}$ & $\begin{array}{l}\text { Allow the } \\
\text { understanding of } \\
\text { children previous } \\
\text { knowledge }\end{array}$ \\
\hline $\begin{array}{l}\text { Second } \\
\text { stage: } \\
\text { children } \\
\text { as } \\
\text { informants }\end{array}$ & $\begin{array}{l}\text { Analyze what } \\
\text { meanings } \\
\text { children } \\
\text { construct } \\
\text { while playing } \\
\text { with the first } \\
\text { design } \\
\text { proposal of } \\
\text { the } \\
\text { EcoSystem } \\
\text { Project }\end{array}$ & $\begin{array}{l}\text { - Open- } \\
\text { ended } \\
\text { questionna } \\
\text { ire } \\
- \\
\text { Conceptua } \\
1 \text { maps } \\
- \text { Semi- } \\
\text { structured } \\
\text { discussion }\end{array}$ & $\begin{array}{l}\text { Children's } \\
\text { misconceptions } \\
\text { and core } \\
\text { meanings }\end{array}$ & $\begin{array}{l}\text { Content } \\
\text { analysis: } \\
\text { grounded } \\
\text { approach }\end{array}$ & $\begin{array}{l}\text { - Identification of } \\
\text { misconceptions } \\
\text { related with the } \\
\text { system (recycling, } \\
\text { wind power) } \\
\text { - Improving of the } \\
\text { physical interaction } \\
\text { - Definition of design } \\
\text { refinements }\end{array}$ & $\begin{array}{l}\text { Allow to } \\
\text { understand how } \\
\text { children build } \\
\text { meaning in } \\
\text { embodied } \\
\text { interaction }\end{array}$ \\
\hline
\end{tabular}




\begin{tabular}{|c|c|c|c|c|c|c|}
\hline $\begin{array}{l}\text { Third } \\
\text { stage: } \\
\text { children } \\
\text { as testers }\end{array}$ & $\begin{array}{l}\text { Evaluate the } \\
\text { effectiveness } \\
\text { of the second } \\
\text { design of the } \\
\text { FUBILE in } \\
\text { supporting } \\
\text { learning }\end{array}$ & $\begin{array}{l}\text { - Open- } \\
\text { ended } \\
\text { questionna } \\
\text { ire } \\
- \\
\text { Conceptua } \\
1 \text { maps } \\
\text { - Semi- } \\
\text { structured } \\
\text { discussion }\end{array}$ & $\begin{array}{l}\text { - Learning } \\
\text { gains } \\
\text { - Children's } \\
\text { misconceptions } \\
\text { and core } \\
\text { meanings }\end{array}$ & $\begin{array}{l}\text { - Pre- } \\
\text { /post-test } \\
\text { between } \\
\text { subjects } \\
\text { experimen } \\
\text { tal design } \\
\text { - Content } \\
\text { analysis: } \\
\text { grounded } \\
\text { approach }\end{array}$ & $\begin{array}{l}\text { - Significant learning } \\
\text { gains between pre- } \\
\text { and post-test } \\
\text { - Significant } \\
\text { difference between } \\
\text { using or not the } \\
\text { FUBILE with } \\
\text { traditional instruction } \\
\text { methods }\end{array}$ & $\begin{array}{l}\text { Allow to } \\
\text { understand how } \\
\text { children had } \\
\text { transformed the } \\
\text { experience into } \\
\text { an object of } \\
\text { knowledge }\end{array}$ \\
\hline
\end{tabular}

\section{Limitations and Future Research}

The Evaluation-Driven approach proved to be highly effective for developing a FUBILE capable of supporting learning of ecosystem relations. Although it is not possible to derive a causal relationship between the proposed design approach and the outcomes of the study, we have shown that our method contributes to improving design and assessment strategies for FUBILEs. However, our proposal represents just one of the possible paths to achieving effective FUBILEs. Further research should be carried out to compare the limitations and benefits of applying different design methods.

In addition, while the present study proposes and discusses a number of elicitation and analysis methods, further research should also address the systematic comparison of different techniques. In our study we analyzed children's interaction with the environment through direct observation and narrative field notes. Although these methods provided useful insights, a deeper methodological effort should be oriented toward improving the analysis of situated interaction in order to better understand embodied meaning construction. Relevant opportunities can be found in methods derived from fine-grain interaction analysis (Streeck, Goodwin, \& LeBaron, 2011) and multimodal analysis (Price \& Jewitt, 2013).

Finally, as a preliminary methodological exploration, this study was not oriented toward developing a product for a specific context (e.g. school or museum). Further research, therefore, should address approaches capable of properly integrating this design method within context-specific requirements.

\section{Conclusion}

We presented an Evaluation-Driven Design approach aimed at integrating children's interpretations as central guidelines to inform the design process. This approach is based on considering user-generated meanings as the minimal unit of analysis and employing them to guide the design process. Its application in the development of a FUBILE, the Ecosystem Project, showed to be an effective strategy to design experiences capable of supporting learning. This study, therefore, confirms the fundamental importance of involving experts and end-users in the design process and suggests how focusing aspects such as interpretative process and situated interactions can meaningfully contribute to research in this area. In the presented study we specifically focused on the learning of aspects related to environmental education. Nonetheless, we suggest that the proposed model can be implemented to address a broader range of learning contents, especially those related with conceptual knowledge.

\section{Acknowledgments}

We thank the Spanish Ministry of Economy and Competitiveness (Grant TIN2014-60599-P) to support the project. We also thank all the participants from local schools for their time and motivation during the participatory design workshop. We are also very grateful for the valuable information and materials on environmental education provided by experts from Fàbrica del Sol, Ecoserveis, Aula Ambiental de la Sagrada Família, Societat Catalana d'Educació Ambiental (SCED) and Centre de Suport a la Innovació i la Recerca Educativa (CESIRE). 


\section{References}

Ackermann, E. K. (2004). CONSTRUCTING KNOWLEDGE AND TRANSFORMING THE WORLD. In M. Tokoro \& L. Steels (Eds.), A learning zone of one's own: Sharing representations and flow in collaborative learning environments. IOS Press.

Ackermann, E. K. (2007). Experience of Artifacts : People's Appropriations / Object's Affordances. In M. Larochelle (Ed.), Ernst von Glasersfeld, Key works on radical constructivism.

Adachi, T., Goseki, M., Muratsu, K., Mizoguchi, H., Namatame, M., \& Sugimoto, M. (2013). Human SUGOROKU : Full-body Interaction System for Students to Learn Vegetation Succession. In Proceeding of the 2013 conference on Interaction design and children - IDC '13 (pp. 364-367).

Anastopoulou, S., Sharples, M., \& Baber, C. (2011). An evaluation of multimodal interactions with technology while learning science concepts. British Journal of Educational Technology, 42(2), 266-290. doi:10.1111/j.1467-8535.2009.01017.x

Antle, A. N. (2013). Research opportunities: Embodied child-computer interaction. International Journal of Child-Computer Interaction, 1(1), 30-36. doi:10.1016/j.ijcci.2012.08.001

Antle, A. N., Corness, G., \& Bevans, A. (2013). Balancing Justice : Comparing Whole Body and Controller-based Interaction for an Abstract Domain. Internation Journal of Arts and Technology, $6(4), 1-21$.

Antle, A. N., Droumeva, M., \& Corness, G. (2008). Playing with The Sound Maker : Do Embodied Metaphors Help Children Learn? In Proceeding of the 2008 International Conference on Interaction design and children - IDC '08 (pp. 178-185).

Barab, S., \& Squire, K. (2004). Design-based research: Putting a stake in the ground. The Journal of the Learning Sciences, 13(1), 1-14.

Barsalou, L. W. (2008). Grounded cognition. Annual Review of Psychology, 59, 617-645.

Berg, C., \& Smith, P. (1994). Assessing students' abilities to construct and interpret line graphs: Disparities between multiple- choice and free response instruments. Science Education, 78(6), 527554.

Carreras, A., \& Parés, N. (2004). Designing an Interactive Installation for Children to Experience Abstract Concepts. In New Trends on Human-Computer Interaction (pp. 33-42).

Charoenying, T., Gaysinsky, A., \& Ryokai, K. (2012). The choreography of conceptual Development in Computer Supported Instructional Environments. In Proceeding of the 2012 International conference on Interaction design and children - IDC '13 (Vol. 4, pp. 162-167).

Clearfield, M. W. (2004). The role of crawling and walking experience in infant spatial memory. Journal of Experimental Child Psychology, 89(3), 214-241. doi:10.1016/j.jecp.2004.07.003

Corbin, J. M., \& Strauss, A. (1990). Grounded theory research: Procedures, Canons and Evaluative Criteria. Qualitative Sociology, 13(1), 3-21.

Dindler, C., \& Iversen, O. S. (2007). Fictional Inquiry-design collaboration in a shared narrative space. CoDesign, 3(4), 213-234.

Druin, A. (2002). The Role of Children in the Design of New Technology. Behaviour and Information Technology, 21(1), 1-25.

Edge, D., Cheng, K., \& Whitney, M. (2013). SpatialEase : Learning Language through Body Motion ( c ). In Proceedings of the SIGCHI Conference on Human Factors in Computing Systems (CHI '13) (pp. 469-472).

Enyedy, N., Danish, J. A., Delacruz, G., \& Kumar, M. 2012. (2012). Learning physics through play in an augmented reality environment. International Journal of Computer-Supported Collaborative Learning, 7(3), 347-378.

Glenberg, A. M. (2010). Embodiment as a unifying perspective for psychology. Wiley Interdisciplinary Reviews: Cognitive Science, 586-596. doi:10.1002/wcs.55 
Glenberg, A. M., Brown, M., \& Levin, J. R. (2007). Enhancing comprehension in small reading groups using a manipulation strategy. Contemporary Educational Psychology, 32(3), 389-399. doi:10.1016/j.cedpsych.2006.03.001

Goldin-Meadow, S. (2011). Learning through gesture. Wiley Interdisciplinary Reviews: Cognitive Science, 2(6), 595-607.

Hanna, L., Risden, K., \& K.J., A. (1997). Guidelines for usability testing with children. Interactions, 4(5), 9-14.

Harrison, S., Sengers, P., \& Tatar, D. (2011). Making epistemological trouble: Third-paradigm HCI as successor science. Interacting with Computers, 23(5), 385-392. doi:10.1016/j.intcom.2011.03.005

Iverson, J. M. (2010). Developing language in a developing body: the relationship between motor development and language development. Journal of Child Language, 37(2), 1-25. doi:10.1017/S0305000909990432.Developing

Jewitt, C. (2013). Multimodal methods for researching digital technologies. In S. Price \& C. Jewitt (Eds.), The SAGE handbook of digital technology research. (pp. 250-265). Los Angeles, CA, USA: SAGE Publications Ltd.

Johnson-glenberg, M. C., Birchfield, D., \& Megowan-romanowicz, C. (2010). SEMI-VIRTUAL EMBODIED LEARNING- REAL WORLD STEM ASSESSMENT. In L. Annetta \& S. Bronack (Eds.), Serious Educational Game Assessment: Practical Methods and Models for Educational Games, Simulations and Virtual Worlds (pp. 225-241). Sense Publications, Rotterdam.

Johnson-glenberg, M. C., Koziupa, T., \& Birchfield, D. (2011a). Games for Learning in Embodied Mixed-Reality Environments : Principles and Results, 129-137.

Johnson-glenberg, M. C., Koziupa, T., \& Birchfield, D. (2011b). Games for Learning in Embodied Mixed-Reality Environments : Principles and Results. In Proceedings of the 7th international conference on Games + Learning + Society Conference (GLS'11) (pp. 129-137).

Jonassen, D. H., \& Rohrer-Murphy, L. (1999). Activity theory as a framework for designing constructivist learning environments. Educational Technology Research and Development, 47(1), 61-79. doi:10.1007/BF02299477

Kim, M. J., \& Maher, M. L. (2008). The impact of tangible user interfaces on spatial cognition during collaborative design. Design Studies, 29(3), 222-253.

Kolb, D. A., Boyatzis, R. E., \& Charalampos, M. (2001). Experiential learning theory: Previous research and new direction. Perspectives on Thinking, Learning, and Cognitive Styles, (216).

Kontra, C., Goldin-Meadow, S., \& Beilock, S. L. (2012). Embodied learning across the life span. Topics in Cognitive Science, 4(4), 731-9. doi:10.1111/j.1756-8765.2012.01221.x

Kozma, R. B. (1994). Will media influence learning? Reframing the debate. Educational Technology Research and Development, 42(2), 7 -19.

Kress, G. (2010). Multimodality. A social semiotic approach to contemporary communication. London, UK: Routledge.

Kynigos, C., Smyrnaiou, Z., \& Roussou, M. (2010). Exploring rules and underlying concepts while engaged with collaborative full-body games. In Proceedings of the 9th International Conference on Interaction Design and Children - IDC '10 (p. 222). New York, New York, USA: ACM Press. doi:10.1145/1810543.1810576

Lucht, M., \& Steffi, H. (2013). Applying HOPSCOTCH as an exer-learning game in English lessons: two exploratory studies. Educational Technology Research and Development, (61), 767 -792. Retrieved from http://download.springer.com/static/pdf/736/art\%253A10.1007\%252Fs11423-013-93083.pdf?auth66=1385030919_d2e250cf1098acb01a5d6addac9dffca\&ext=.pdf

Lucignano, L., Cuendet, S. Schwendimann, B. A., Shirvani Boroujeni, M. Dehler, J., \& Dillenbourg, P. (2014). My hands or my mouse: Comparing a tangible and graphical user interface using eyetracking data. In Fablearn 2014 (No. EPFL-CONF-204226).

Malinverni, L., Lopez Silva, B., \& Pares, N. (2012). Impact of embodied interaction on learning processes: design and analysis of an educational application based on physical activity. In Proceedings of the 11th International Conference on Interaction Design and Children (IDC '12). (pp. 60-69). 
Malinverni, L., \& Pares, N. (2014). Learning of Abstract Concepts through Full-Body Interaction: A Systematic Review. Educational Technology \& Society, 17(4), $100-116$.

Malinverni, L., \& Pares, N. (2015). The Medium Matters: the Impact of Full-Body Interaction on the Socio-Affective Aspects of Collaboration. In IDC'15 Proceedings of the 2015 conference on Interaction design and children. ACM. doi:10.1145/2771839.2771849

Markopoulos, P., Read, J., MacFarlane, S., \& Höysniemi, J. (2008). Evaluating Children's Interactive Products. Evaluating Children's Interactive Products. San Francisco, CA, USA: Morgan Kaufmann Publishers Inc.

Muller, M. J., \& Druin, A. (2003). Participatory Design : The Third Space in HCI. In Human-computer interaction: Development process (Vol. 4235, pp. 1-70).

Nathan, M., \& Robinson, C. (2001). Considerations of learning and learning research: Revisiting the "media effects" debate. Journal of Interactive Learning Research, 12(1), 69-88.

Nesset, V., \& Large, A. (2004). Children in the information technology design process: A review of theories and their applications. Library \& Information Science Research, 26(2), 140-161. doi:10.1016/j.lisr.2003.12.002

Nicol, D. J., \& Macfarlane- Dick, D. (2006). Formative assessment and self- regulated learning: a model and seven principles of good feedback practice. Studies in Higher Education, 31(2), 199-218.

Overton, W. F. (2004). Embodied Development: Ending the Nativsim-Empiricism Debate. In C. Garcia Coll, E. Bearer, \& R. Lerner (Eds.), Nature and Nurture: The Complex Interplay of Genetic and Environmental Influences on Human Behavior and Development (pp. 201-223). Mahwah, NJ: Lawrence Erlbaum Associates.

Paolo, E. A. Di, Rohde, M., \& Jaegher, H. De. (2007). Horizons for the Enactive Mind : Values, Social Interaction, and Play Horizons for the Enactive Mind: Values, Social. Horizons, (April).

Papert, S. (1980). Mindstorms: Children, computers, and powerful ideas. Basic Books, Inc.

Price, S., \& Jewitt, C. (2013). A multimodal approach to examining "embodiment" in tangible learning environments. In Proceedings of the 7th International Conference on Tangible, Embedded and Embodied Interaction (TEI '13). (pp. 43-50).

Reeves, T. C., Herrington, J., \& Oliver, R. (2005). Design Research: A Socially Responsible Approach to Instructional Technology Research in Higher Education. Journal of Computing in Higher Education, 16(2), 97-116.

Reeves, T., \& Okey, J. (1996). Alternative assessment for constructivist learning environments. Constructivist Learning Environments: Case Studies in Instructional Design, 191-202.

Revelle, G. (2013). Applying Developmental Theory and Research to the Creation of Educational Games. In Digital Games: A Context for Cognitive Development. New Directions for Child and Adolescent Development (pp. 31-40). doi:10.1002/cad

Rogoff, B. (1990). Apprenticeship in thinking: Cognitive development in social context. Oxford, UK:Oxford University Press.

(Authors)

Streeck, J., Goodwin, C., \& LeBaron, C. (2011). Embodied interaction in the material world: An introduction. In Embodied interaction (pp. 1-26).

Wang, F., \& Hannafin, M. J. (2005). Design-based research and technology-enhanced learning environments. Educational Technology Research and Development, 53(4), 5-23.

Wilson, M. (2002). Six views of embodied cognition. Psychonomic Bulletin \& Review, 9(4), 625-36. Retrieved from http://www.ncbi.nlm.nih.gov/pubmed/12613670

Zuckerman, O., \& Resnick, M. (2003). A physical interface for system dynamics simulation. In CHI '03 Extended Abstracts on Human Factors in Computing Systems (pp. 810-811). New York, NY, USA: ACM. doi:10.1145/765891.766005 
